\title{
The Design of Hearing and hypnosis all-in-one Machine
}

\author{
Shiyong Zheng ${ }^{1,}$, , Zhao $\mathrm{Li}^{2}$, b, Biqing $\mathrm{Li}^{3}$ \\ ${ }^{1}$ College of Computer Science and Information Engineering, Hezhou University, Hezhou Guangxi \\ 542899, China \\ ${ }^{2}$ Management Engineering Department, Guangxi vocational and technical college of \\ communications, Liuzhou Guangxi 530000, China \\ ${ }^{3}$ College of Mechanical and Electronic Engineering, Hezhou University, Hezhou Guangxi 542899, \\ China. \\ a229292710@qq.com, bjanliful@163.com
}

Keywords: Chip CD4069, 51 single chip microcomputer, Inverter circuit.

\begin{abstract}
This page proposed a hearing and hypnosis all-in-one machine which used CD4069 as the core, it can be achieved Hearing and hypnosis. This design is mainly use the six COS/MOS inverter circuits of CD4069 chip, converted the voice of the outside world which collected by MIC to electrical signals and amplifier, then released with headphones, so as to complete the hearing function. The circuit could produce a low frequency signal, the frequency is close to the rain voice frequency, converted into sound signal, then play out by the headphones. People can hear a sound which similar to the rain voice, it make people relaxed, so as to achieve hypnotic effect. The all-in-one machine also design a remind alarm.
\end{abstract}

\section{Introduction}

The hearing aid is a kind of equipment that can improve the ability to hear others, which is helpful to the people who are with hearing issues, dealing with their hearing impairment. In the face of increasingly realistic society, in order to try to improve the abilities to adapt and survive for the people with hearing loss, and better the equality between whom and normal people, the scientists pay more attention to the development and improvement of hearing aid.

\section{System Design Requirements}

The design is mainly shown by two functions, people can select the function mode through pressing the two buttons:

(1) Press button 1, then it works as a hearing aid. The principle is to convert external sound signal into an electrical signal, after amplified by the built-in amplifier, then the electrical signal is output through the earphone.

(2) Press button 2, then it works as a sleeping aid. The principle is to generate a low-frequency signal, after amplified by the built-in amplifier, it will play some music like it's raining, which is functional to help people relax, so as to aid people to fall asleep.

\section{Scheme Selection}

Scheme 1: it is to use the odd-stage negative feedback amplifier which is composed of the hex inverter CD4069 to amplify external sound in the circuit, and get the $0.7 \mathrm{HZ}$ low-frequency signal amplified at the same time, so as to play the functions as hearing aid and sleeping aid.

Scheme 2: Using MSP430FG439 as the master chip, the chip comes with internal AD and DA between the conversion function and programmable amplifier. By this scheme, it can make the system completed in one chip, because the microcontroller works slowly, and at the same time, which will bring about some difficulties in digital filtering, so this scheme is not recommended.

Based on the overall consideration about the two said schemes, scheme 1 will be used in this design. 


\section{System Hardware Selection}

Features of Chip CD4069.Chip CD4069 is mainly composed of 6 COS/MOS inverter circuits. CD4069 is generally used in the circuits which do not require medium power TTL driving or logic level converting as a universe inverter. It is the output mode of chip pins, voltage and current below:

About SCM system chip-STC89C52RC

STC89C52RC is the latest SCM system chip issued by STCmicro, which is low power consumption, high speed and super jam-proof, and what's more, its instruction codes are not only fully compatible to the traditional SCM8051, but also its machine cycle is available for modes selection with 6 cycle or 12 cycle.

\section{Hardware Circuit Design}

This design is mainly using CD4069 chip and STC89C52RC chip to reach the implementation of two functions as hearing \& sleeping aid and alarm.

Working Principle of Hardware Circuit

The general principle diagram of the design as shown above: it is an all-in-one machine (AIO), with functions of hearing aid, sleeping aid with an alarm feature. It carries out the hearing \& sleeping aid functions via CD4069, uses the STC89C52 to realize the alarm function.

Design Principle of Hearing \& Sleeping Aid

Because the circuit is mainly to produce the results to be achieved by the ratio characteristics between elements of the circuit itself, so the circuit element is for the sensitivity of certain requirements, if there is a ratio reading or other components are installed on the circuit, then which probably interfere right effect which is generated by the circuit any minute, even the original function can be covered, resulting in a failure of the circuit. Therefore, it is necessary to pay attention to all kinds of interference factors that could affect the results when the circuit is extended or additional functions are added.

Design Principle of Extended Function Part. Schematic Diagram of Primary Functional Design is as shown in the above figure, when the power supply is on, then the circuit starts to be normally initializing, LCD display reads "00:00:00", if we do not do any adapting or setting to the time, the clock will be working normally. If you press the button 1, you are selecting which part of the time you are trying to set, set the time where the cursor blinks, second, minute and hour. And pressing the button 2 and button 3 is to raise and reduce the value of time, they are for time setting. Once the time is set, then the time will go normally according to the standard procedure, the time reach the alarm time, then the buzzer will ring forever unless it is stopped manually. Button4 is a reset button, if you press the reset button, the time will be reinitialized, and you need to set the time again. If you don't do any task transfer, then to the next set time, the clock will ring again. The alarm function mainly is carried out through reset, setting buttons, position-buttons to set the alarm time, so as to achieve the alarm buzzer function。

Minimum System of SCM. Actually, the Minimum System of SCM is mainly composed of SCM, crystal oscillating circuit and reset circuit, but in the actual design, we are partial to adding keystroke input and display output into said circuit, so as to build up a minimum system.

The above diagram shows the main components of the system: oscillator. Oscillator is the guarantee to decide whether the SCM can work normally or not, if the oscillator does not work, then the system will not work normally; if the oscillator does not work right, which looks irregularly, then there will be a time error while the system is working, which will result in a communication failure of the circuit. And at the same time, there is a high-gain inverting amplifier in the SCM, which is specially used to build up the oscillator, lead pin XTAL1 is its input end, lead pin XTAL2 is its output end. It is a circuit which is composed of one crystal oscillator and two ceramic capacitors, and this circuit makes a stable free-running generator, clock rate can cast influence to operating speed of SCM, and the operation of each functional part of the SCM is based on the clock control signal. What we need to pay extra attention to is that the connecting end of the two ceramic capacitors must be grounded. 


\section{Debugging}

There are several procedures for making and debugging of hardware as follows:

First, through our own collection of painting materials, try to perfect the improvement of the principle diagram, and edit the layout of $\mathrm{PCB}$, in order to make a more attractive one, we can place the same software in the same position, except for the ones with particular position requirement, and then make the Corrosion of the circuit board.

Secondly, it is to buy all kinds of components required for the circuit, and then according to the system PCB diagram, weld all of the components on the circuit board. Before welding, we must first double-check whether the models, specifications and working data of the components meet the requirements of the system. In order to prevent from wrong welding, we need to correctly distinguish the pin direction of the components or the positive and negative poles of the components, so as to prevent the wrong welding from work inappropriately.

\section{Summary}

At the beginning of the design, we must first find some relevant materials about design, conduct classification and analysis on them, at least, we need to learn about its constitution \& configuration, what role they act in the circuit and what need to be paid special attention to, such as, what the functions the chip is with itself, or what role it plays in the circuit, all of which are what we need to get a full understanding of.

\section{Acknowledgements}

This work is supported the following fund:

2016 The project of improving the basic ability of young teachers in Colleges and universities in Guangxi: "Design and development of electronic commerce platform of agricultural products based on Semantic Technology" (No,KY2016YB455).

2015 college students' innovative training program: "Research on the application of value added travel experience in the mobile terminal of the "ethnic custom travel' in Guangxi" (No 201511838070); \& “The design and development HeYuanTong Campus Mobile Phone APP based on Android" (No 201511838034).

Project of scientific research and technology development project of Hezhou: "Design and implementation of agricultural products e-commerce platform based on Semantic Technology" (No, Hekeneng 1506006).

\section{References}

[1] B.Q LI, Y.F LING, H.Y ZHANG, S.Y ZHENG: The Design and Realization of Cherry Tomato Harvesting Robot Based on IOT. International Journal of Online Engineering, 12(12), 23, (2016).

[2] B.Q LI, W.L GUAN, S.Y Zheng, X.G Yue: OPTIMISATION DESIGN OF CORN PRECISION SEEDER BASED ON MULTI-ROUTE AND MULTI-CHANNEL CONTROL. JOURNAL OF THE BALKAN TRIBOLOGICAL ASSOCIATION, 21(4A), 1215, (2015).

[3] B.Q Li, et al, The Design Implementation of the APP of Experiencing Guangxi Folk Custom, in: PROCEEDINGS OF THE 2016 INTERNATIONAL CONFERENCE ON ECONOMICS AND MANAGEMENT INNOVATIONS, Wuhan, China, 2016, PP.47-50.

[4] B.Q Li, et al, Intelligent Control Management System and Its Application, in: PROCEEDINGS OF THE 2016 INTERNATIONAL CONFERENCE ON ECONOMICS AND MANAGEMENT INNOVATIONS, Wuhan, China, 2016, PP.68-71.

[5] B.Q Li, et al, Design and Implementation of Tanks War Game Based on the Android Platform, in: PROCEEDINGS OF THE 2016 2ND WROKSHOP ON ADVANCED RESEARCH AND TECHNOLOGY IN INDUSTRY APPLICATIONS, Dalian, China, 2016, PP.963-966.

[6] B.Q Li, et al, Design of a Tea Garden Antifreezing Control System, in: PROCEEDINGS OF THE 2016 6TH INTERNATIONAL CONFERENCE ON MACHINERY, MATERIALS, ENVIR 
ONMENT, BIOTECHNOLOGY AND COMPUTER (MMEBC), Tianjin, China, 2016, PP.736738.

[7] B.Q Li, et al, Design of Electronic Compass, in: PROCEEDINGS OF THE 2016 6TH INTERNATIONAL CONFERENCE ON MACHINERY, MATERIALS, ENVIRONMENT, BIOTECHNOLOGY AND COMPUTER (MMEBC), Tianjin, China, 2016, PP.1240-1243.

[8] B.Q Li, et al, Research of Automatically Light-Adjusting Lamp, in: PROCEEDINGS OF THE 2016 INTERNATIONAL CONFERENCE ON COMPUTER ENGINEERING, INFORM ATION SCIENCE \& APPLICATION TECHNOLOGY (ICCIA 2016), Guilin, China, 2016, PP.249-252.

[9] B.Q Li, et al, The Design and Realization of Fruit Harvesting Robot Based on IOT, in: PROCEEDINGS OF THE 2016 INTERNATIONAL CONFERENCE ON COMPUTER ENGINEERING,INFORMATION SCIENCE \& APPLICATION TECHNOLOGY (ICCIA 2016), Guilin, China, 2016, PP.261-264.

[10] B.Q Li, et al, A New Type of Automatic Opening and Closing Light-Operated Curtain, in: PROCEEDINGS OF THE 2016 INTERNATIONAL CONFERENCE ON MECHATRONICS ENGINEERING AND INFORMATION TECHNOLOGY(ICMEIT), Xian, China, 2016, PP.6669.

[11] B.Q Li, et al, Design of the Intelligent Air Humidifier, in: PROCEEDINGS OF THE 2016 INTERNATIONAL CONFERENCE ON MECHATRONICS ENGINEERING AND INFORM ATION TECHNOLOGY (ICMEIT), Xian, China, 2016, PP.201-203.

[12] S.Y Zheng, et al, Social Work in Teen Addiction Correction Services Research under the New Situation, in: PROCEEDINGS OF THE 2015 4TH NATIONAL CONFERENCE ON ELECTRICAL, ELECTRONICS AND COMPUTER ENGINEEERING (NCEECE 2015), Xian, China, 2015, PP.252-255.

[13] S.Y Zheng, et al, Digital Display Design of Ethnic Clothing of Nanling, in: PROCEEDINGS OF THE 4TH INTERNATIONAL CONFERENCE ON MECHATRONICS, MATERIALS. CHEMISTRY AND COMPUTER ENGINEERING 2015(ICMMCCE 2015), Xian, China, 2015, PP.2805-2808.

[14] S.Y Zheng, et al, Design and Implementation of Supermarket Personnel Management System Based On Java, in: PROCEEDINGS OF THE 2015 INTERNATIONAL CONFERENCE ON EDUCATION,MANAGEMENT AND COMPUTING TECHNOLOGY, Tianjin, China, 2015, PP.1724-1727. 